\title{
QUALIDADE FISIOLÓGICA DE SEMENTES DE FEIJÃO EM FUNÇÃO DE SISTEMAS DE MANEJO DE SOLO E ADUBAÇÃO FOLIAR COM BORO
}

\author{
Fabiana Lima Abrantes ${ }^{1}$, Marco Eustáquio de $\mathrm{Sá}^{2}$, Mariana Pina da Silva ${ }^{3}$, Lilian Christian \\ Domingues de Souza ${ }^{4}$, Natália Arruda ${ }^{5}$ \\ ${ }^{1}$ Pesquisadora de Pós Doutorado na UNOESTE, Presidente Prudente (SP). \\ ${ }^{2}$ Professor Dr. do Depto. de Fitotecnia, Tecnologia de Alimentos e Sócio Economia da FEIS / UNESP \\ Campus de Ilha Solteira (SP). \\ ${ }^{3}$ Doutora Científica Regional da Universidade de Rio Verde (GO). \\ ${ }^{4}$ Professora Dra. da AEMS de Três Lagoas (MS). \\ ${ }^{5}$ Doutoranda pela ESALQ / USP Piracicaba (SP).
}

RESUMO: O fator climático exerce grande influência na produção de sementes de feijão, porém outros fatores como a ação do ambiente solo, consequência de seu manejo, associado à nutrição adequada da planta, podem levar a resultados expressivos na obtenção de produto de melhor qualidade. O trabalho teve como objetivo avaliar a influência de sistemas de manejo de solo e da aplicação foliar de boro sobre a qualidade fisiológica de sementes de dois cultivares de feijão (Alvorada e Carioca Precoce). O delineamento experimental utilizado foi o de blocos casualizados num esquema em faixas com quatro repetições, sendo os tratamentos constituídos por dois sistemas de manejo do solo (semeadura convencional e plantio direto em fase de implantação na palhada de milheto) e cinco doses de boro ( 0 ; 132 ;

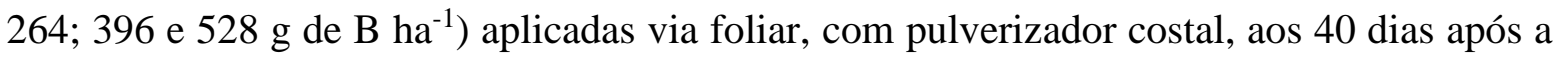
emergência, o que corresponde ao estádio fenológico $\mathrm{R}_{5}-\mathrm{R}_{6}$ para o Carioca Precoce e $\mathrm{R}_{5}$ para o IAC Alvorada. A qualidade fisiológica das sementes de feijão foi avaliada através dos testes de germinação, envelhecimento acelerado e teste de frio sem solo. As plantas cultivadas no sistema de semeadura direta originam sementes com melhor germinação, e as doses de boro não interferem na germinação. As doses de boro associada ao sistema de semeadura melhoram o desempenho das sementes de feijão cultivar Alvorada e Carioca Precoce no teste de envelhecimento acelerado mediante aumento das doses de boro.

Palavras-chave: Germinação. Phaseolus vulgaris. Semeadura convencional. Semeadura direta. Vigor.

\section{COMMON BEAN'S PHYSIOLOGICAL SEED QUALITY OF RELATION MANAGEMENT SYSTEMS OF SOIL AND FOLIAR BORON APPLICATION}

\begin{abstract}
The climatic factor has great influence on seed production of common beans, but other factors such as the action of the soil environment, a result of its management, coupled with the proper plant nutrition, can lead to significant results in obtaining better quality product. The study aimed to evaluate the influence of different soil and foliar application of boron on the physiological quality of seeds of two cultivars of common beans (Carioca Precoce and IAC Alvorada) systems. The experimental design was a randomized block scheme with four replications in bands, with treatments consisting of two systems of
\end{abstract}

Cultura Agronômica, Ilha Solteira, v.24, n.2, p.167-180, 2015 
soil (conventional tillage and sowing under implementation in millet straw) management and five doses $(0,132,264,396$ and $528 \mathrm{~g} \mathrm{~B}$ ha-1) applied as foliar application, by spraying at 40 days after emergence, which corresponds to the growth stage R5-R6 for Carioca Precoce and R5 for the IAC Alvorada. The physiological quality of common bean seeds was assessed by the standard germination test, accelerated aging and cold germination test. Plants grown in the tillage system originate with better seed germination, and boron levels do not interfere with germination. The boron levels associated with the seeding system improves the performance of common bean seeds cultivar Alvorada and Carioca Precoce the accelerated aging by increasing doses of boron test.

Key words: Germination. Phaseolus vulgaris. Conventional seeding. Tillage. Vigor.

\section{INTRODUÇÃO}

No cultivo do feijão de inverno, a irrigação possibilita a obtenção de produtividades cerca de três vezes superiores às obtidas em outras épocas de cultivo. No período da entressafra, se obtém melhores preços, facilidade de mão-de-obra e produção de sementes de alta qualidade. Assim, o feijoeiro tornou-se uma das principais culturas utilizadas na entressafra em sistemas irrigados, na região Central e no Sudeste do Brasil (BARBOSA FILHO et al., 2001).

O feijoeiro é considerado exigente em nutrientes, sendo fundamental que eles sejam colocados à disposição da planta em tempo e local adequados; a adubação foliar é uma importante alternativa para o seu fornecimento (ROSOLEM et al., 1990).

A carência de boro é muito comum no País, particularmente em solos arenosos e pobres em matéria orgânica (MALAVOLTA, 1980). A quantidade de boro requerida para a formação da semente, geralmente, é maior do que a necessária para o crescimento vegetativo (MARSCHNER, 1995). E as informações sobre os efeitos da aplicação foliar de boro na germinação de sementes são escassos, Silva et al. (2006), Ambrosano et al. (1999) e Reis et al. (2008) não observaram efeito das doses de boro na germinação das sementes.

O boro atua no metabolismo e no transporte de carboidratos; participa também no processo reprodutivo, afetando a polinização, o crescimento do tubo polínico e a produção de frutos e sementes (COETZER et al., 1990).

Trabalhos relacionando adubação e nutrição das plantas com a qualidade fisiológica das sementes são raros e contrastantes (CARVALHO; NAKAGAWA, 2000), ficando evidente a necessidade da execução de mais estudos sobre nutrição e a produção de sementes de alta qualidade, já que a qualidade das sementes está em grande parte, relacionada com a nutrição adequada da planta mãe, portanto, pode ser influenciada pelo ambiente em que as sementes se desenvolvem.

A qualidade da semente compreende muitas características como viabilidade, vigor, teor de água, maturidade, danificação mecânica, infecções por patógenos, tamanho e longevidade (POPINIGIS, 1985), e a interação dos componentes genético, físico, sanitário e 
fisiológico é que expressam a qualidade da semente (CARVALHO; NAKAGAWA, 2000).

Na cultura do feijão, são crescentes os trabalhos confrontando os diversos sistemas de manejo de solo, visando obter informações quanto ao ganho de produtividade, principalmente o plantio direto em relação a outros, em especial ao preparo convencional (STONE; MOREIRA, 2000; STONE; MOREIRA, 2001; ARF et al., 2004). Porém, pouco se sabe sobre a influência dos sistemas de manejo de solo na qualidade fisiológica das sementes, por isso o objetivo foi avaliar a influência de sistemas de manejo de solo e da aplicação foliar de boro sobre a qualidade fisiológica de sementes de dois cultivares de feijão (Alvorada e Carioca Precoce).

\section{MATERIAL E MÉTODOS}

Esse trabalho foi conduzido na Fazenda de Ensino, Pesquisa e Extensão da Faculdade de Engenharia/UNESP, Campus de Ilha Solteira, localizada no Município de Selvíria/MS, utilizando a mesma área e, também, as mesmas parcelas, nos dois anos. O local apresenta como coordenadas geográficas $51^{\circ} 22^{\prime} \mathrm{W}$ e $20^{\circ} 22^{\prime} \mathrm{S}$, e altitude aproximadamente de 335 m. O clima é do tipo Aw, segundo a classificação de Köeppen, definido como tropical úmido com estação chuvosa no verão e seca no inverno.

O solo do local é considerado, de acordo com a classificação da Embrapa (2006), como Latossolo Vermelho Distroférrico típico argiloso. Para a análise química do solo foram realizadas duas amostragens: uma na área destinada à semeadura convencional e outra na área de semeadura direta, antes da semeadura do feijoeiro, na camada de 0-0,20 m seguindo a metodologia proposta por Raij et al. (2001), cujos resultados da área com convencional são: matéria orgânica: $12,2 \mathrm{~g} / \mathrm{dm}^{3} ; \mathrm{pH}\left(\mathrm{CaCl}_{2}\right): 4,6 ; \mathrm{P}: 16,2 \mathrm{mg} / \mathrm{dm}^{3} ; \mathrm{K}^{+}: 2,1$ $\mathrm{mmol}_{\mathrm{c}} / \mathrm{dm}^{3} ; \mathrm{Ca}^{2+}: 19,0 \mathrm{mmol}_{\mathrm{c}} / \mathrm{dm}^{3} ; \mathrm{Mg}^{2+}: 13,0 \mathrm{mmol}_{\mathrm{c}} / \mathrm{dm}^{3} ; \mathrm{H}^{+}+\mathrm{Al}^{3+}: 38,8 \mathrm{mmol}_{\mathrm{c}} / \mathrm{dm}^{3} \mathrm{e}$ saturação por bases de 46,8\%. E da área de semeadura direta são: matéria orgânica: 10,9 $\mathrm{g} / \mathrm{dm}^{3} ; \mathrm{pH}\left(\mathrm{CaCl}_{2}\right): 4,4 ; \mathrm{P}: 18,4 \mathrm{mg} / \mathrm{dm}^{3} ; \mathrm{K}^{+}: 1,5 \mathrm{mmol}_{\mathrm{c}} / \mathrm{dm}^{3} ; \mathrm{Ca}^{2+}: 24,0 \mathrm{mmol}_{\mathrm{c}} / \mathrm{dm}^{3} ; \mathrm{Mg}^{2+}$ : $10,0 \mathrm{mmol}_{\mathrm{c}} / \mathrm{dm}^{3} ; \mathrm{H}^{+}+\mathrm{Al}^{3+}: 39,2 \mathrm{mmol}_{\mathrm{c}} / \mathrm{dm}^{3}$ e saturação por bases de $47,5 \%$.

Para a semeadura do milheto como planta de cobertura o solo foi preparado convencionalmente com uma aração e duas gradagens, e as sementes semeadas mecanicamente, no dia 12/12/2008, com espaçamento de $0,17 \mathrm{~m}$, distribuindo-se, em média, 80 sementes $\mathrm{m}^{-1}$ de sulco.

Quando o milheto atingiu o estádio de florescimento, em 18/02/2009, realizou-se a ceifa das plantas através de roçadora, após esse manejo as plantas continuaram se desenvolvendo e as rebrotas foram manejadas em maio, época de semeadura do feijão. A dessecação das rebrotas do milheto foi realizada aproximadamente sete dias antes da semeadura do feijão utilizando herbicida glyphosate na dose de $1.920 \mathrm{~g}$ i.a ha- $\mathrm{ha}^{-1}$ posteriormente realizou-se a ceifa dessas rebrotas.

Após a dessecação do milheto foi demarcada a área destinada à semeadura convencional e direta, para posterior instalação do experimento de feijão. No manejo do solo utilizando semeadura direta (plantio direto em fase de implantação) as sementes de

Cultura Agronômica, Ilha Solteira, v.24, n.2, p.167-180, 2015 
feijão foram semeadas sobre a palhada do milheto, e na semeadura convencional o solo foi preparado com 1 aração e 2 gradagens, incorporando a palhada da cultura antecessora (milheto) ao solo.

O experimento de feijão foi conduzido no período outono-inverno de 2009 , com uso de irrigação por aspersão, aplicando-se uma lâmina de água de $15 \mathrm{~mm}$, duas vezes por semana. Durante o período de desenvolvimento do feijoeiro as ocorrências de chuvas foram muito pequenas com uma ocorrência um pouco mais acentuada próxima a época de colheita, conforme dados climáticos apresentados na Figura 1.

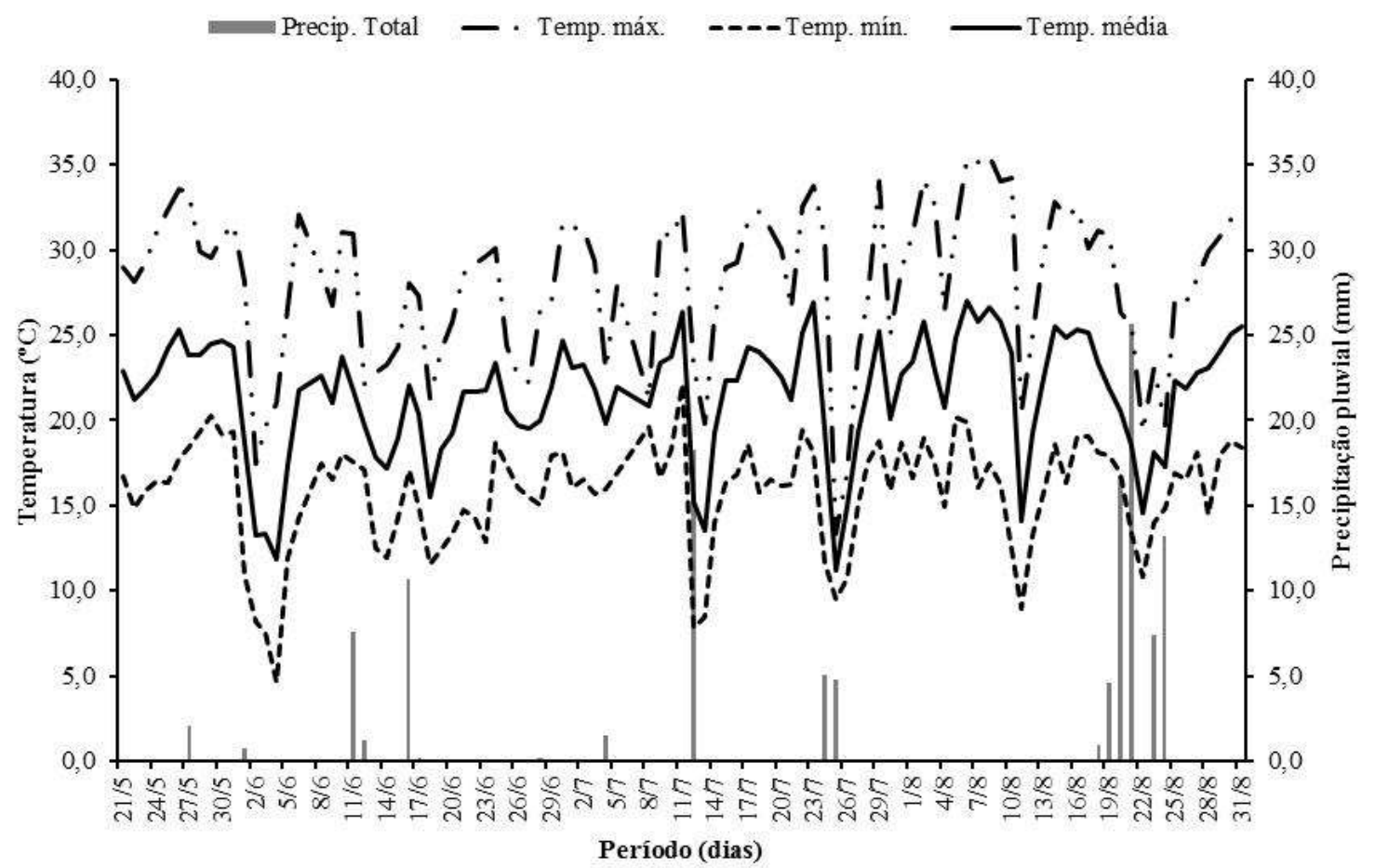

Figura 1. Valores diários de precipitação pluvial $(\mathrm{mm})$, temperatura máxima, mínima e média $\left({ }^{\circ} \mathrm{C}\right)$, coletados durante a condução do experimento. Selvíria - MS, 2009.

As parcelas foram constituídas de sete linhas de $5 \mathrm{~m}$ de comprimento com espaçamento de $0,45 \mathrm{~m}$, sendo consideradas como área útil cinco linhas, desprezando-se 0,5 $\mathrm{m}$ em cada extremidade das linhas, onde foram realizadas a coleta de plantas e a colheita para determinação da produtividade.

Para a condução do experimento foi escolhido dois cultivares com diferente hábito de crescimento, mas com bom desempenho na região, sendo eles: Carioca Precoce que tem plantas de crescimento determinado e IAC Alvorada que tem plantas de crescimento indeterminado e semi ereto. A semeadura do feijão foi realizada no dia 21/05/2009, mecanicamente, em sulcos de aproximadamente $0,05 \mathrm{~m}$ de profundidade, distribuindo-se, em médias, 15 sementes $\mathrm{m}^{-1}$, para cada cultivar e a emergência das plantas ocorreu em $27 / 05 / 2009$. As sementes utilizadas foram tratadas com carboxin + thiran $(200+200 \mathrm{~g}$ i.a para $100 \mathrm{~kg}$ de sementes). A adubação de semeadura foi realizada mecanicamente, e por isso adotou-se a mesma quantidade de adubo para os dois sistemas, e utilizou-se $250 \mathrm{~kg} \mathrm{ha}^{-1}$ 
da fórmula 08-28-16, levando-se em consideração os resultados da caracterização química do solo e as necessidades da cultura conforme recomendações de Ambrosano et al. (1997).

$\mathrm{Na}$ adubação de cobertura, levou-se em consideração o nível de produtividade esperada de 3,5 t ha ${ }^{-1}$, constante da recomendação de Ambrosano et al. (1997) e foi realizada aos 23 DAE (20/06/2009) para os dois cultivares, aplicando-se $90 \mathrm{~kg} \mathrm{ha}^{-1} \mathrm{de} \mathrm{N}$, tendo como fonte a uréia. $\mathrm{O}$ adubo foi distribuído manualmente e irrigado em seguida, para minimizar as perdas de nitrogênio por volatilização.

Os tratamentos fitossanitários foram realizados sempre que necessários, e a adubação foliar boro ocorreu aos 40 dias após a emergência (DAE), para os dois cultivar, o que corresponde ao estádio fenológico $\mathrm{R}_{5}-\mathrm{R}_{6}$ para o Carioca Precoce e $\mathrm{R}_{5}$ para o IAC Alvorada, sendo empregadas as seguintes doses de Boro: 0; 132; 264; 396 e $528 \mathrm{~g}$ de B ha ${ }^{-1}$. A aplicação foi realizada no período da manhã com o auxílio de um pulverizador costal de 20 litros, aplicando-se um volume de calda equivalente a $300 \mathrm{~L} \mathrm{ha}^{-1}$. Das cinco linhas que formavam a área útil colheram-se, manualmente, duas linhas de $4 \mathrm{~m}$ de comprimento, quando cada cultivar atingiu o estádio $\mathrm{R}_{9}$, caracterizando a maturidade fisiológica. As outras linhas foram utilizadas para coleta de plantas para análises foliares e componentes da produção. Após a colheita manual, as plantas foram levadas para secagem a pleno sol e submetidas à trilha manual e as sementes foram limpas com o auxílio de peneiras e acondicionadas em sacos de papel. As sementes obtidas foram armazenadas em câmara seca (aproximadamente $20^{\circ} \mathrm{C}$ e $40 \%$ de umidade relativa) e avaliadas após a colheita, mediante: teste de germinação: realizado com quatro subamostras de 50 sementes para cada tratamento, em rolos de papel Germitest, sendo que o papel foi umedecido com quantidade de água equivalente a 2,5 vezes a sua massa e foram levados para o germinador à $25 \pm 3^{\circ} \mathrm{C}$. As contagens foram realizadas aos cinco e nove dias após a instalação do teste, de acordo com os critérios estabelecidos pelas Regras de Análise de Sementes (BRASIL, 2009); teste de envelhecimento acelerado: realizado com quatro subamostras de 50 sementes para cada tratamento, pelo método proposto por Marcos Filho (1999), colocando-se 200 sementes sobre uma tela de inox ajustada dentro de uma caixa plástica transparente, contendo no fundo $40 \mathrm{~mL}$ de água destilada. Após a colocação da tampa, as caixas foram levadas a estufa regulada à temperatura de $41^{\circ} \mathrm{C}$, onde permaneceram por 48 horas. Transcorrido esse período, as sementes foram semeadas seguindo o mesmo procedimento descrito para o teste de germinação e as plântulas normais foram avaliadas cinco após a implantação do teste (período para primeira contagem da germinação); teste de frio sem solo: realizado com quatro subamostras de 50 sementes para cada tratamento, em rolos de papel Germitest e mantidas em câmara fria a $10^{\circ} \mathrm{C}$ por sete dias e levadas ao germinador à $25 \pm 3^{\circ} \mathrm{C}$, e a contagem realizada no quinto dia após a transferência para o germinador.

$\mathrm{Na}$ condução do experimento de campo, o delineamento experimental utilizado foi blocos casualizados, em faixas, com quatro repetições, e os fatores estudados foram: dois sistemas de semeadura e cinco doses de Boro; quando realizado o experimento em laboratório para verificar a qualidade das sementes foi retirada uma subamostra de 50 sementes de cada repetição, totalizando 200 sementes por tratamento para cada teste realizado.

Cultura Agronômica, Ilha Solteira, v.24, n.2, p.167-180, 2015 
Os dados foram submetidos à análise de variância pelo teste F. As médias referentes aos sistemas de semeadura foram comparadas pelo teste de Tukey a 5\% de probabilidade, enquanto os efeitos das doses de boro foram avaliados pela análise de regressão, adotandose como critério para escolha do modelo a magnitude dos coeficientes de regressão significativos ao nível de 5\%. Para a análise estatística dos dados foi utilizado o programa SISVAR (FERREIRA, 2008).

\section{RESULTADOS E DISCUSSÃO}

Na Tabela 1 encontram-se os resultados obtidos nos testes germinação, envelhecimento acelerado e teste de frio, realizados para avaliar a qualidade fisiológica das sementes de feijão cv IAC Alvorada e Carioca Precoce em função dos sistemas de manejo e das doses de boro aplicados via foliar no período "de inverno" no ano de 2009. Considerando o teste de germinação, observou-se interação significativa entre os sistemas de manejo e as doses de boro via foliar para porcentagem de germinação de sementes de feijoeiro cv Alvorada (Tabela 1).

Tabela 1. Valores médios e coeficientes de variação obtidos na análise de variância para germinação, envelhecimento acelerado e teste de frio em sementes de feijão (\%), cultivares Alvorada e Carioca Precoce, em função dos sistemas de manejo do solo e doses de boro via foliar. Ilha Solteira, SP, 2009.

\begin{tabular}{|c|c|c|c|c|c|c|}
\hline \multirow[t]{2}{*}{ Causa de variação } & \multicolumn{2}{|c|}{ Germinação (\%) } & \multicolumn{2}{|c|}{ E. Acelerado (\%) } & \multicolumn{2}{|c|}{ Teste de Frio (\%) } \\
\hline & Alvorada & Carioca & Alvorada & Carioca & Alvorada & Carioca \\
\hline \multicolumn{7}{|c|}{ Sistema de manejo do solo (A) } \\
\hline Semeadura convencional & 76,0 & $88,3 b^{1}$ & 81,2 & 85,7 & 74,0 & 90,5 \\
\hline Semeadura direta & 77,6 & $91,7 \mathrm{a}$ & 90,7 & 93,3 & 80,8 & 91,5 \\
\hline \multicolumn{7}{|l|}{$\overline{\text { Doses }\left(\mathrm{g} \mathrm{de} \mathrm{B} \mathrm{ha}^{-1}\right)(\mathrm{B})}$} \\
\hline 0 & 66,2 & $90,0^{(1)}$ & 76,2 & 81,0 & 73,5 & 94,0 \\
\hline 132 & 80,0 & 89,0 & 82,2 & 86,0 & 80,0 & 91,0 \\
\hline 264 & 90,5 & 86,7 & 86,2 & 90,0 & 81,7 & 91,5 \\
\hline 396 & 69,0 & 92,5 & 91,0 & 94,0 & 69,7 & 90,7 \\
\hline 528 & 78,2 & 91,7 & 94,0 & 96,5 & 82,0 & 87,7 \\
\hline Regressão & $* *$ & $\mathrm{RQ}^{2 *}$ & $* *$ & $* *$ & $* *$ & $* *$ \\
\hline \multirow[t]{2}{*}{ Interação A x B } & $* *$ & ns & $* *$ & $* *$ & $* *$ & $* *$ \\
\hline & \multicolumn{6}{|c|}{ Valores de F } \\
\hline Sistemas de manejo (A) & $6,40^{\mathrm{ns}}$ & $12,56^{*}$ & $253,04 * *$ & $722,00 * *$ & $346,80 * *$ & $15,00 *$ \\
\hline Doses (B) & $81,95 * *$ & $5,39 *$ & $951,24 * *$ & $177,69 * *$ & $9,69 * *$ & $10,06 * *$ \\
\hline Interação A x B & $21,87 * *$ & $2,94^{\mathrm{ns}}$ & $8,570 * *$ & $35,57 * *$ & $10,462 * *$ & $10,18 * *$ \\
\hline $\mathrm{CV} \%(\mathrm{~A})$ & 2,60 & 3,37 & 2,20 & 1,00 & 1,49 & 0,90 \\
\hline $\mathrm{CV} \%(\mathrm{~B})$ & 3,92 & 3,09 & 0,75 & 1,47 & 6,44 & 2,18 \\
\hline $\mathrm{CV} \%(\mathrm{~A} \times \mathrm{B})$ & 3,85 & 3,10 & 1,57 & 0,76 & 4,58 & 2,27 \\
\hline
\end{tabular}

${ }^{1}$ Médias seguidas de letras distintas, na coluna, diferem estatisticamente entre si, pelo teste de Tukey a 5\% de probabilidade. ns, *e ** são: não significativo, significativo a $5 \%$ e a $1 \%$ de probabilidade pelo teste $\mathrm{F}^{2}{ }^{2} \mathrm{y}=$ $92,15-2,94 x+0,61 x^{2}$ com $R^{2}=0,48^{*}$.

Cultura Agronômica, Ilha Solteira, v.24, n.2, p.167-180, 2015 
No desdobramento da interação (Tabela 2) observa-se que, de maneira geral, as sementes obtidas no sistema de semeadura direta apresentaram maior porcentagem de germinação independente da dose de boro, porém com diferença significativa apenas na testemunha e nas doses de 264 e $396 \mathrm{~g}$ de B ha ${ }^{-1}$, e ao avaliar o efeito da aplicação de boro em cada sistema verificou-se que as mesmas não diferiram significativamente para a porcentagem de germinação das sementes de feijão cv Alvorada.

Tabela 2. Desdobramento da interação sistemas de semeadura e doses boro via foliar para porcentagem de germinação, cultivar IAC Alvorada. Ilha Solteira, SP, 2009.

\begin{tabular}{lcccccc}
\hline Sistemas de manejo do solo & \multicolumn{4}{c}{ Doses $\left(\mathrm{g} \mathrm{ha}^{-1}\right)$} & \multirow{2}{*}{ Regressão } \\
\cline { 2 - 6 } & 0 & 132 & 264 & 396 & 528 & \\
\hline Semeadura convencional & $63,0 \mathrm{~b}$ & $79,0 \mathrm{a}$ & $88,0 \mathrm{~b}$ & $60,0 \mathrm{~b}$ & $78,0 \mathrm{a}$ & $\mathrm{ns}$ \\
Semeadura direta & $69,5 \mathrm{a}$ & $81,0 \mathrm{a}$ & $93,0 \mathrm{a}$ & $78,0 \mathrm{a}$ & $78,5 \mathrm{a}$ & $\mathrm{ns}$ \\
\hline
\end{tabular}

Médias seguidas de letras distintas, na coluna, diferem estatisticamente entre si, pelo teste de Tukey a 5\% de probabilidade. ns: não significativo a $5 \%$ de probabilidade pelo teste $\mathrm{F}$. DMS=4,23.

Em relação ao cultivar Carioca Precoce (Tabela 1) a porcentagem de germinação foi influenciada pelos sistemas de manejo e pelas doses de boro aplicadas via foliar. Em relação aos sistemas de manejo verifica-se que o sistema de semeadura direta proporcionou a maior porcentagem de germinação. E no que refere à aplicação de boro foliar os dados se ajustaram a uma função quadrática $\mathrm{y}=92,15-2,94 \mathrm{x}+0,61 \mathrm{x}^{2}$ com $\mathrm{R}^{2}=0,48^{*}$, porém do ponto de vista biológico não é um efeito explicável, tendo em vista que com o aumento da dose, até certo ponto, ocorreu diminuição na germinação e posteriormente acréscimo mediante aumento das doses.

Os resultados do presente trabalho não corroboram os obtidos por Ambrosano et al. (1999), que não encontraram efeito positivo da aplicação de boro na qualidade fisiológica de sementes de feijão, medida por meio do teste de germinação e do número de plântulas anormais. Segundo Marschner (1995) e Rerkasen e Jamjod (1997), a reserva de boro nas sementes também é extremamente importante, pois sementes deficientes têm baixo poder germinativo e, além disso, irão gerar plântulas anormais.

Houve interação significativa para porcentagem de germinação após o teste de envelhecimento acelerado entre sistemas de manejo e doses de boro via foliar para feijoeiro cv. Alvorada e no desdobramento da interação (Tabela 3 e Figura 2), observa-se que o sistema de plantio direto apresentou maior porcentagem de plântulas normais no teste de envelhecimento acelerado em todas as doses de boro utilizadas.

Para o desdobramento sistemas de manejo dentro de doses de boro via foliar foi possível constatar aumento linear na porcentagem de plântulas normais do teste de envelhecimento acelerado tanto para a semeadura convencional quanto para a semeadura direta, ou seja, com o aumento das doses de boro houve um aumento na resposta de vigor, medido pelo teste de envelhecimento acelerado, e quanto ao sistema de semeadura na semeadura direta foi onde observou-se os maiores valores de germinação após o teste de envelhecimento acelerado, sendo todos superiores a $80 \%$.

Cultura Agronômica, Ilha Solteira, v.24, n.2, p.167-180, 2015 
Tabela 3. Desdobramento da interação entre sistemas de manejo e doses boro via foliar na germinação após o teste de envelhecimento acelerado em sementes de feijão (\%), cultivar IAC Alvorada. Ilha Solteira, SP, 2009.

\begin{tabular}{lcccccc}
\hline Sistemas de manejo do solo & \multicolumn{4}{c}{ Doses $\left(\mathrm{g}\right.$ de B ha $\left.{ }^{-1}\right)$} & \multirow{2}{*}{ Regressão } \\
\cline { 2 - 6 } & 0 & 132 & 264 & 396 & 528 & \\
\hline Semeadura convencional & $69,5 \mathrm{~b}^{1}$ & $77,0 \mathrm{~b}$ & $81,5 \mathrm{~b}$ & $87,0 \mathrm{~b}$ & $91,0 \mathrm{~b}$ & $\mathrm{RL}^{* * 1}$ \\
Semeadura direta & $83,0 \mathrm{a}$ & $87,5 \mathrm{a}$ & $91,0 \mathrm{a}$ & $95,0 \mathrm{a}$ & $97,0 \mathrm{a}$ & $\mathrm{RL}^{* * 2}$ \\
\hline
\end{tabular}

${ }^{1}$ Médias seguidas de letras distintas, na coluna, diferem estatisticamente entre si, pelo teste de Tukey a 5\% de probabilidade. RL: Regressão linear. ${ }^{(1)} \mathrm{y}=65,30+5,30 \mathrm{x}\left(\mathrm{r}^{2}=0,99 * *\right) ;{ }^{(2)} \mathrm{y}=80,05+3,55 \times\left(\mathrm{r}^{2}=0,99 * *\right) . * *$ : significativo a $1 \%$ de probabilidade pelo teste $\mathrm{F}$. DMS $=2,23$.

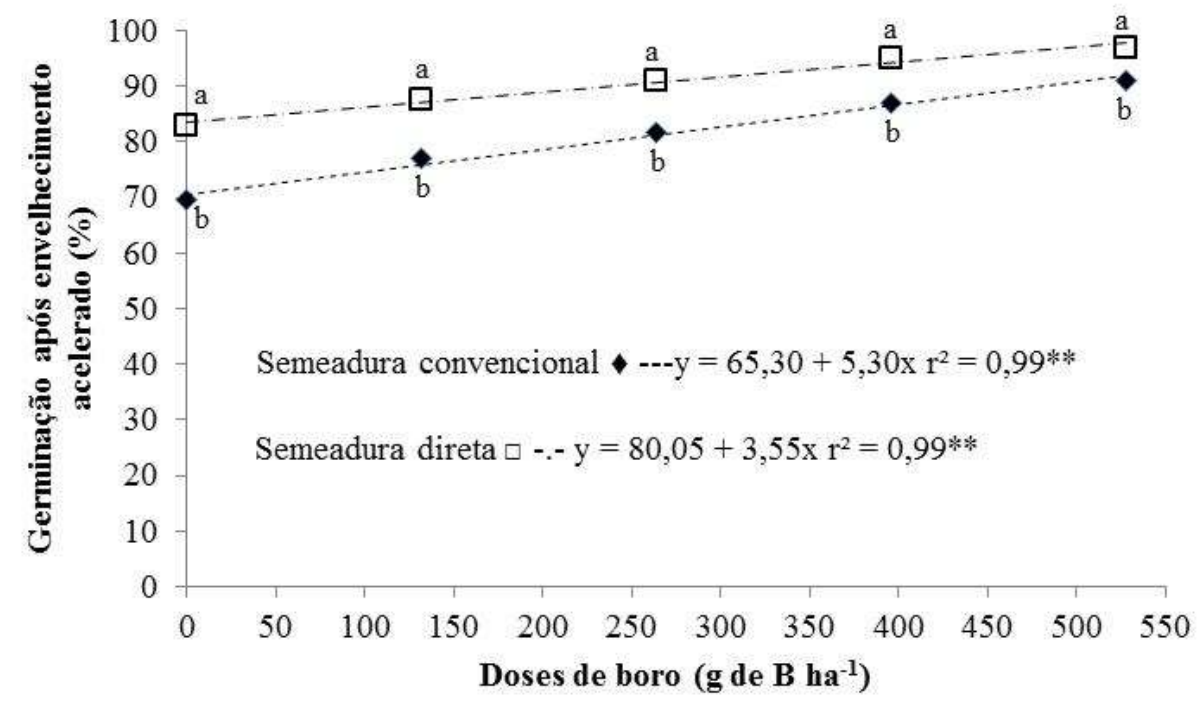

Médias seguidas de letras distintas diferem estatisticamente entre si, pelo teste de Tukey a $5 \%$ de probabilidade. ${ }^{* *}$ : significativo a $1 \%$ de probabilidade pelo teste $\mathrm{F}$.

Figura 2. Desdobramento da interação entre sistemas de manejo e doses boro via foliar na germinação após o teste de envelhecimento acelerado em sementes de feijão (\%), cultivar IAC Alvorada. Ilha Solteira, SP, 2009.

Para o cultivar Carioca Precoce também foi verificado diferença estatística significativa entre os sistemas de manejo e doses de boro via foliar em relação à porcentagem de plântulas normais no teste de germinação após o teste de envelhecimento acelerado (Tabela 4 e Figura 3). O sistema de semeadura direta apresentou maior porcentagem de germinação no teste de envelhecimento acelerado em todas as doses de boro utilizadas. E no desdobramento sistemas de manejo dentro de doses de boro via foliar foi possível constatar aumento linear na porcentagem de germinação do teste de envelhecimento acelerado tanto para a semeadura convencional quanto para a semeadura direta, demonstrando que o aumento das doses de boro via foliar propiciou aumento na porcentagem de germinação do teste de envelhecimento acelerado.

Embora ainda não exista um padrão mínimo de germinação para sementes após o envelhecimento acelerado, as sementes apresentavam boa qualidade e vigor, já que a germinação estava acima de $80 \%$ que é o mínimo exigido em um teste padrão de germinação para a comercialização de sementes, portanto as sementes, mesmo depois de 
submetidas à condição de estresse apresentaram germinação acima do mínimo exigido em um teste padrão de germinação.

Diferente do observado nesse trabalho para o envelhecimento acelerado Silva et al. (2006), avaliando a aplicação foliar de boro e cálcio no feijoeiro não observaram efeito das doses de boro no envelhecimento acelerado.

Tabela 4. Desdobramento da interação entre sistemas de manejo e doses boro via foliar na germinação após o teste de envelhecimento acelerado em sementes de feijão (\%), cultivar Carioca Precoce. Ilha Solteira, SP, 2009.

\begin{tabular}{|c|c|c|c|c|c|c|}
\hline \multirow[t]{2}{*}{ Sistemas de manejo do solo } & \multicolumn{5}{|c|}{ Doses $\left(\mathrm{g} \mathrm{de} \mathrm{B} \mathrm{ha}^{-1}\right)$} & \multirow[t]{2}{*}{ Regressão } \\
\hline & 0 & 132 & 264 & 396 & 528 & \\
\hline Semeadura convencional & $77,0 b^{1}$ & $81,0 \mathrm{~b}$ & $85,0 \mathrm{~b}$ & $90,5 \mathrm{~b}$ & $95,0 \mathrm{~b}$ & $\mathrm{RL}^{* * 1}$ \\
\hline Semeadura direta & $85,0 \mathrm{a}$ & $91,0 \mathrm{a}$ & $95,0 \mathrm{a}$ & $97,5 \mathrm{a}$ & $98,0 \mathrm{a}$ & $\mathrm{RL}^{* * 2}$ \\
\hline
\end{tabular}

${ }^{1}$ Médias seguidas de letras distintas, na coluna, diferem estatisticamente entre si, pelo teste de Tukey a 5\% de probabilidade. RL: Regressão linear. ${ }^{(1)} \mathrm{y}=72,05+4,55 \mathrm{x}$ com $\mathrm{r}^{2}=0,99^{* *}$; ${ }^{(2)} \mathrm{y}=83,55+3,25 \mathrm{x}$ com $\mathrm{r}^{2}=$ $0,90 * *$ **: significativo a $1 \%$ de probabilidade pelo teste $\mathrm{F}$. DMS $=1,56$.

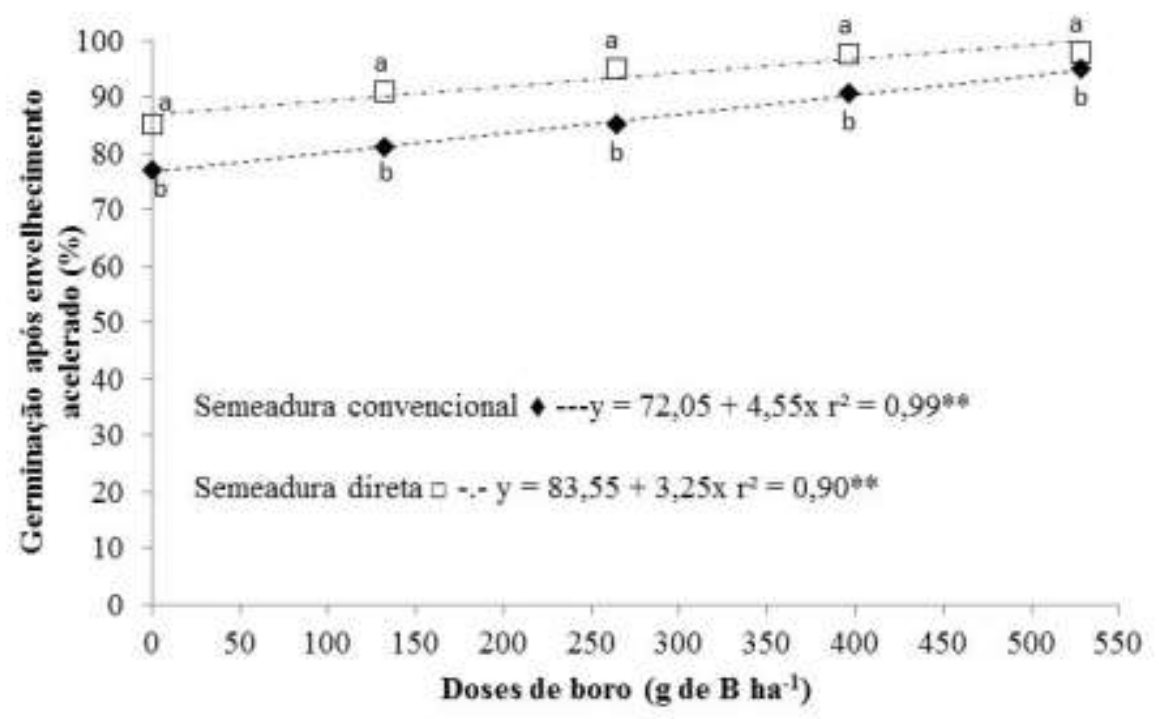

Médias seguidas de letras distintas diferem estatisticamente entre si, pelo teste de Tukey a 5\% de probabilidade. **: significativo a $1 \%$ de probabilidade pelo teste $\mathrm{F}$.

Figura 3. Desdobramento da interação entre sistemas de manejo e doses boro via foliar na germinação após o teste de envelhecimento acelerado em sementes de feijão (\%), cultivar Carioca Precoce. Ilha Solteira, SP, 2009.

No teste de frio constatou-se interação significativa entre sistemas de manejo e doses de boro via foliar para feijoeiro cv. IAC Alvorada e no desdobramento (Tabela 5) observou-se que, de maneira geral, o sistema de semeadura direta apresentou maior porcentagem de germinação no teste de frio na maioria das doses de boro utilizadas, e para as doses dentro de cada sistema de semeadura não foi observado efeito significativo.

No desdobramento da interação significativa sistemas de manejo e doses de boro via foliar para a cultivar Carioca Precoce (Tabela 6) observou-se que somente na dose de $264 \mathrm{~g}$ de $\mathrm{B} \mathrm{ha}{ }^{-1} \mathrm{o}$ sistema de semeadura direta apresentou maior porcentagem de germinação no 
teste de frio, já para o efeito das doses dentro de cada sistema não foi verificado efeito significativo do boro, ou seja, com o teste de frio não foi possível detectar diferença de vigor em função das diferentes doses de boro utilizadas.

Tabela 5. Desdobramento da interação sistemas de manejo e doses boro via foliar na germinação após o teste de frio em sementes de feijão (\%), cultivar IAC Alvorada. Ilha Solteira, SP, 2009.

\begin{tabular}{lcccccc}
\hline Sistemas de manejo do solo & \multicolumn{4}{c}{ Doses $\left(\mathrm{L} \mathrm{p.c} \mathrm{ha} \mathrm{ha}^{-1}\right)$} & \multirow{2}{*}{ Regressão } \\
\cline { 2 - 5 } & 0 & 132 & 264 & 396 & 528 & \\
\hline Semeadura convencional & $66,5 \mathrm{~b}$ & $73,5 \mathrm{~b}$ & $82,5 \mathrm{a}$ & $71,0 \mathrm{a}$ & $76,5 \mathrm{~b}$ & $\mathrm{~ns}$ \\
Semeadura direta & $80,5 \mathrm{a}$ & $86,5 \mathrm{a}$ & $81,0 \mathrm{a}$ & $68,5 \mathrm{a}$ & $87,5 \mathrm{a}$ & $\mathrm{ns}$ \\
\hline
\end{tabular}

Médias seguidas de letras distintas, na coluna, diferem estatisticamente entre si, pelo teste de Tukey a 5\% de probabilidade. ns: não significativo. $\mathrm{DMS}=4,91$.

Tabela 6. Desdobramento da interação significativa sistemas de manejo x doses boro via foliar para teste de frio em sementes de feijão (\%), cultivar Carioca Precoce. Ilha Solteira, SP, 2009.

\begin{tabular}{|c|c|c|c|c|c|c|}
\hline \multirow[t]{2}{*}{ Sistemas de manejo do solo } & \multicolumn{5}{|c|}{ Doses (L p.c ha-1) } & \multirow[t]{2}{*}{ Regressão } \\
\hline & 0 & 132 & 264 & 396 & 528 & \\
\hline Semeadura convencional & $93,0 \mathrm{a}$ & $91,0 \mathrm{a}$ & $87,0 \mathrm{~b}$ & $91,0 \mathrm{a}$ & $86,5 \mathrm{a}$ & ns \\
\hline Semeadura direta & $95,0 \mathrm{a}$ & $91,0 \mathrm{a}$ & $96,0 \mathrm{a}$ & $90,5 \mathrm{a}$ & 89,0 a & ns \\
\hline
\end{tabular}

A melhor qualidade fisiológica das sementes na semeadura direta pode ter sido proporcionada pela maior proteção do solo, menor evaporação, menor temperatura do solo e, portanto, aumento na capacidade de armazenamento de água, enquanto que no sistema de semeadura convencional não existe a camada de massa de matéria seca sobre o solo e com isso há uma maior evaporação da água do solo, consequentemente menor umidade. Como a irrigação era igual, em número de dias e volume de água nos dois sistemas de semeadura, onde foi realizada a semeadura direta a camada de palha mantinha a umidade do solo por mais tempo do que na semeadura convencional, sendo assim a área com semeadura direta estaria mais úmida até que fosse realizada a próxima irrigação, o que pode ter favorecido a obtenção de sementes de melhor qualidade no sistema de semeadura direta.

Os resultados observados nesse trabalho são semelhantes, em parte, com os resultados encontrados por Kappes et al. (2008) que trabalhando com doses e épocas de aplicação foliar de boro em soja verificaram que a germinação e o vigor avaliado pelos testes de primeira contagem da germinação e índice de velocidade de germinação não foram influenciadas pela aplicação de boro, corroborando com os resultados observados nesse trabalho para germinação. Bevilaqua et al. (2002) trabalhando com aplicação foliar de Ca e B em soja também não verificaram efeito desses nutrientes na qualidade fisiológica das sementes de soja.

Reis et al. (2008) trabalhando com doses e modo de aplicação de boro verificaram que a aplicação de boro, tanto foliar como em cobertura não interferem na germinação e no vigor avaliados pelos testes de primeira contagem da germinação, emergência em campo,

Cultura Agronômica, Ilha Solteira, v.24, n.2, p.167-180, 2015 
índice de velocidade de emergência e condutividade elétrica das sementes de feijão produzidas em solos de cerrado.

\section{CONCLUSÃO}

As plantas cultivadas no sistema de semeadura direta originam sementes com melhor germinação, e as doses de boro não interferem na germinação.

As doses de boro associada ao sistema de semeadura melhoram o desempenho das sementes de feijão cultivar Alvorada e Carioca Precoce no teste de envelhecimento acelerado mediante aumento das doses de boro.

\section{REFERÊNCIAS BIBLIOGRÁFICAS}

AMBROSANO, E. J.; TANAKA, R. T.; MASCARENHAS, H. A. A.; RAIJ, B. Van; QUAGGIO, J. A.; CANTARELLA, H. Leguminosas e oleaginosas. In: RAIJ, B. Van.; CANTARELlA, H.; QUAGGIO, J. A.; FURLANI, A. M. C. Recomendações de adubação e calagem para o Estado de São Paulo. 2. ed. Campinas: IAC, 1997. cap. 19, p. 187-204 (Boletim técnico, 100).

AMBROSANO, E. J.; AMBROSANO, G. M. B.; WUTKE, E. B.; BULISANI, E. A.; MARTINS, A. L. M.; SILVEIRA, L. C. P. Efeitos da adubação nitrogenada e com micronutrientes na qualidade de sementes do feijoeiro cultivar IAC - Carioca. Bragantia, Campinas, v. 58, n. 2, p.393-399, 1999.

ARF, O.; RODRIGUES, R. A. F.; SÁ, M. E.; BUZETTI, S.; NASCIMENTO, V. Manejo do solo, água e nitrogênio no cultivo de feijão. Pesquisa Agropecuária Brasileira, Brasília, v. 39, n. 2, p.131-138, 2004.

BARBOSA FILHO, M. P.; FAGERIA, N. K.; SILVA, O. F. Aplicação de nitrogênio em cobertura no feijoeiro irrigado. Santo Antônio de Goiás: Embrapa Arroz e Feijão. 8p. (Circular técnica, 49), 2001.

BEVILAQUA, G. A. P.; SILVA FILHO, P. M.; POSSENTI, J. C. Aplicação foliar de cálcio e boro e componentes de rendimento e qualidade de sementes de soja. Ciência Rural, Santa Maria, v. 32, n. 1, p.31-34, 2002.

BRASIL. Ministério da Agricultura e da Reforma Agrária. Regras para análise de sementes. Brasília: SNDA/DNDV/CLAV, 2009. 395 p.

CARVALHO, N. M.; NAKAGAWA, J. Sementes: ciência, tecnologia e produção. 4 ed. Jaboticabal, FUNEP, 2000. 588 p.

Cultura Agronômica, Ilha Solteira, v.24, n.2, p.167-180, 2015 
COETZER, L. A.; ROBBERTSE, P. J.; STOFFBERG, E.; HOLTZHAUSEN, L. S.; BERNARD, R. O. The effect of boron on reproduction in tomato (Lycopersicum esculentum) and bean (Phaseolus vulgaris). Plant Grond, Tydeskr, v. 7, n. 4, p.212-217, 1990.

EMPRESA BRASILEIRA DE PESQUISA AGROPECUÁRIA - EMBRAPA. Sistema brasileiro de classificação de solos. 2. ed. Rio de Janeiro: Embrapa, 2006. 306 p.

FERREIRA, D. F. SISVAR: um programa para análises e ensino de estatística. Revista Symposium, Lavras, v. 6, n. 2, p.36-41, 2008.

KAPPES, C.; GOLO, A. L.; CARVALHO, M. A. C. Doses e épocas de aplicação foliar de boro nas características agronômicas e na qualidade de sementes de soja. Scientia Agraria, Curitiba, v. 9, n. 3, p.291-297, 2008.

MALAVOLTA, E. Elementos de nutrição mineral de plantas. São Paulo: Agronômica Ceres, 1980. 251 p.

MARCOS FILHO, J. Teste de envelhecimento acelerado. In: KRZYZANOWSKI, F.C.; VIEIRA, R.D.; FRANÇA NETO, J.B. (Ed.). Vigor de sementes: conceitos e testes. Londrina: ABRATES, 1999. cap. 3, p. 3.1-3.24.

MARSCHNER, H. Mineral nutrition of higher plants. 2nd ed. San Diego: Academic Press. 1995.889 p.

POPINIGIS, F. Fisiologia da semente. 2 ed. Brasília: AGIPLAN, 1985. 289 p.

RAIJ, B. Van.; ANDRADE, J. C.; CANTARELLA, H.; QUAGGIO, J. A. Análise química para avaliação da fertilidade de solos tropicais. Campinas: Instituto Agronômico, 2001. $284 \mathrm{p}$.

REIS, C. J.; SORATTO, R. P.; BISCARO, G. A.; KULCZYNSKI, S. M.; SILVEIRA, D. F. Doses e modos de aplicação de boro na produção e qualidade fisiológica de sementes de feijão em solo de cerrado. Revista Ceres, Viçosa, v. 55, n. 4, p.258-264, 2008.

RERKASEN, B.; JAMJOD, S. Genotypic variation in plant response to low boron and implication for plant breeding. Plant and Soil, Dordrecht, v. 193, n. 1, p.169-180, 1997.

ROSOlEM, C. A.; BOARETTO, A. E.; NAKAGAWA, J. Adubação foliar do feijoeiro. VIII. Fontes e doses de cálcio. Científica, São Paulo, v. 18, n. 2, p.81-86, 1990.

SILVA, T. R. B.; SORATTO, R. P.; BÍSCARO, T.; LEMOS, L. B. Aplicação foliar de boro e cálcio no feijoeiro. Científica, São Paulo, v. 34, n. 1, p.46-52, 2006.

Cultura Agronômica, Ilha Solteira, v.24, n.2, p.167-180, 2015 
STONE, L. F.; MOREIRA, J. A. A. Efeitos de sistemas de preparo do solo no uso de água e na produtividade do feijoeiro. Pesquisa Agropecuária Brasileira, Brasília, v. 35, n. 4, p.835-841, 2000.

STONE, L. F.; MOREIRA, J. A. A. Resposta do feijoeiro em cobertura, sob diferentes lâminas de irrigação e preparos de solo. Pesquisa Agropecuária Brasileira, Brasília, v. 36, n. 3, p.473-481, 2001.

VIEIRA, R. F.; VIEIRA, C.; RAMOS, J. A. O. Produção de sementes de feijão. Viçosa: EPAMIG/EMBRAPA, 1993. $131 \mathrm{p}$. 
